05

\title{
Особенности деформирования круглых тонкопленочных мембран и экспериментальное определение их эффективных характеристик
}

\author{
() А.А. Дедкова, ${ }^{1}$ П.Ю. Глаголев, ${ }^{1}$ Е.Э. Гусев, ${ }^{1}$ Н.А. Дюжев, ${ }^{1}$ В.Ю. Киреев, ${ }^{1}$ С.А. Лычев, ${ }^{2}$ Д.А. Товарнов ${ }^{1}$ \\ ${ }^{1}$ Национальный исследовательский университет „МИЭТ“, \\ 124498 Зеленоград, Москва, Россия \\ ${ }^{2}$ Институт проблем механики им. А.Ю. Ишлинского РАН, \\ 119526 Москва, Россия \\ e-mail: dedkova@ckp-miet.ru
}

Поступило в Редакцию 26 апреля 2021 г.

В окончательной редакции 26 апреля 2021 г.

Принято к публикации 26 апреля 2021 г.

Рассмотрены особенности тонкопленочных мембран, сформированных над круглыми отверстиями в кремниевых подложках с помощью Бош-процесса травления. Из-за напряженного состояния исходных пленок мембраны имеют сложную форму. Для расчета механических характеристик мембраны посредством анализа зависимости прогиба мембраны $w$ от поданного на нее избыточного давления $P$ необходимо определение непосредственно на мембране: ее диаметра, толщин составляющих ее слоев, изменения рельефа поверхности мембраны по всей ее площади по мере увеличения давления $P$. На примере $p-\mathrm{Si}^{*} / \mathrm{SiN}_{x} / \mathrm{SiO}_{2}$ и $\mathrm{SiN}_{x} / \mathrm{SiO}_{2} / \mathrm{SiN}_{x} / \mathrm{SiO}_{2}$-мембран показано определение диаметра мембраны и толщин составляющих слоев. Использованы методы спектральной эллипсометрии, рентгеновского энергодисперсионного микроанализа, оптической профилометрии и оптической микроскопии. Показано влияние особенностей условий закрепления мембран на их напряженно-деформированное состояние, проведена оценка посредством численного моделирования. Разработана методика измерений и расчета механических характеристик мембран, имеющих начальный прогиб. Результат расчета показан на примере мембраны с начальным прогибом $2 \mu \mathrm{m}-$ $\mathrm{SiN}_{x} / \mathrm{SiO}_{2} / \mathrm{SiN}_{x} / \mathrm{SiO}_{2}$ и мембраны с начальным прогибом $30 \mu \mathrm{m}-\mathrm{Al} / \mathrm{SiO}_{2} / \mathrm{Al}$.

Ключевые слова: тонкие пленки, мембрана, дефект, механические характеристики, механические напряжения, деформация, модуль Юнга, модуль упругости, прогиб, микроэлектромеханические системы, МЭМС, круглая мембрана, кремниевая подложка, оптическая профилометрия, избыточное давление.

DOI: 10.21883/JTF.2021.10.51357.121-21

\section{Введение}

В настоящее время большое внимание уделяется вопросам анализа напряженно-деформированного состояния, возникающего в микроэлектромеханических системах (МЭМС). Объектами исследования являются закрепленные на контуре круглые в плане мембраны. Подобные мембраны могут быть получены из предварительно созданных на кремниевой подложке тонких пленок, после глубокого сквозного травления кремния с обратной стороны пластины. При этом форма подверженной травлению области определяет форму контура мембраны. Диаметр сформированного отверстия на несколько порядков величины превышает толщину мембраны. Полученные таким образом мембраны применяются, в частности, в рентгеновской оптике $[1,2]$, в качестве чувствительных элементов датчиков различных физических величин [3-5] и др.

При расчетах и проектировании устройств на базе МЭМС необходимо использовать математические модели, способные прогнозировать поведение микроструктур при различных физических и механических воздействиях. Этот математический аппарат существенно отличается от классической механики ввиду масштабных факторов и до конца в настоящее время не разработан. По этой причине требуется развитие математических моделей и их верификация в соответствии с экспериментальными данными. В этой связи в настоящий момент актуальной задачей является разработка методик идентификации параметров тонкопленочных мембран.

Анализ закрепленных на контуре мембран следует осуществлять с учетом их фактических геометрических размеров и реальных условий закрепления, возникающих в процессе их изготовления. Существенное влияние масштабного фактора, в частности, поверхностной энергии, изменения эффективных свойств и др., проявляющееся при размерах порядка нескольких сотен нанометров - отмечено во многих исследованиях [6-18]. Кроме того, на специфику распределения остаточных напряжений в тонкостенных структурах могут оказывать существенное влияние физико-механические аспекты процесса их создания (роста, травления и пр.) [19-21].

Классические уравнения теории пластин и оболочек не учитывают этого масштабного фактора, поэтому их применение для оценки механических характеристик тонкопленочных структур не оптимально. Известно большое количество приближенных методов оценки напряженного состояния мембран при конечных деформа- 
циях, но они, как правило, предполагают определенную и весьма простую форму деформации, например по сферической поверхности [22,23], что далеко не всегда согласуется с экспериментальными данными. В этой связи предпочтительно использовать приближенные модели, в которых эффективные свойства определяются по относительно простым формулам. Подобный подход развивается в настоящей работе.

Настоящая работа посвящена описанию важных для последующего анализа экспериментально наблюдаемых особенностей мембран, сформированных над круглыми отверстиями в кремниевых подложках.

\section{1. Изготовление мембран}

Исследуемые мембраны представляют собой одиночные пленки или наборы пленок суммарной толщиной порядка единиц микрометров и менее, диаметром порядка миллиметра и менее.

Исследуемые мембраны изготавливались [24] с использованием технологии на основе Бош-процесса (Bosch-process) сквозного травления кремниевых подложек через маски, сформированные на их обратной стороне. Указанный процесс является высокоселективным к материалам мембраны и маски и обеспечивает высокую анизотропию травления кремния за счет последовательного чередования стадий реактивного ионноплазменного травления и плазмохимического осаждения за счет изменения состава газовой среды и напряжения на подложкодержателе. Пример сформированной структуры четырехслойной мембраны приведен на рис. 1.

Неравномерность травления по всей кремниевой пластине и необходимость удаления полимера из глубоких отверстий приводят к большому времени перетрава. Это вызывает подтрав мембраны и изменение ее толщины по диаметру.

После травления высвобождается область пленки над круглым отверстием, которая и становится мембраной. В связи с наличием начальных механических напряжений в слоях структуры до травления [25-27] наблюдает-

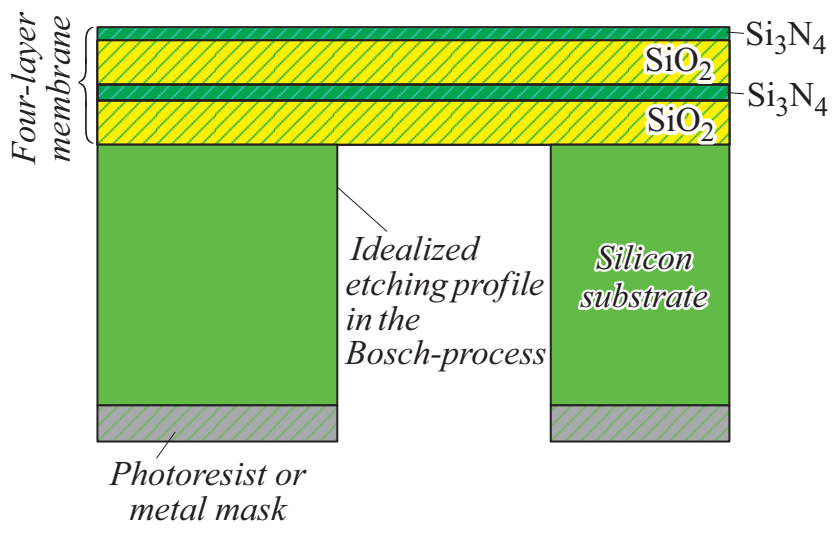

Рис. 1. Формирование тонкопленочной четырехслойной мембраны на кремниевой подложке с помощью Бош-процесса

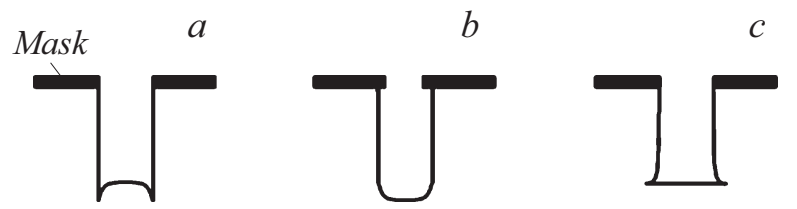

Рис. 2. Различные варианты профилей нижней поверхности мембран в зависимости от режимов Бош-процесса: $a$ профиль с пристеночными микроканавками (micro-trenching) на поверхности дна; $b$ - профиль с искривленной поверхностью дна (curved bottom surface); $c$ - профиль с боковыми выемками (notching).

ся ненулевой начальный прогиб мембраны [28-30]. Фактически перераспределение внутренних усилий приводит к дополнительным искажениям мембран. При этом в области мембраны происходит увеличение площади поверхности пленки.

В зависимости от режима Бош-процесса могут быть получены различные профили травления нижней поверхности мембраны (рис. 2) [24]. Они влияют на условия закрепления мембраны вдоль опорного контура.

\section{2. Методики испытаний и расчета мембран. Определяемые параметры}

Исследовалось поведение мембран под воздействием избыточного давления, подаваемого со стороны отверстий в кремнии. Для испытаний использовался стенд на базе оптического профилометра [2,31,32], осуществляющий равномерную подачу и фиксацию величины давления, а также определяющий прогиб мембраны. Под прогибом понимается наибольшая разница по высоте между областью мембраны и областью подложки (основания мембраны), наблюдаемая в центре мембраны.

В связи с широкой известностью теории пластин и оболочек, а также простотой предлагаемых для расчетов выражений, они часто используются для анализа МЭМС структур [33-41]. Для случая прогибов абсолютно гибкой мембраны, характеризующихся наличием растягивающих сил, радиального перемещения и удлинения срединной плоскости:

$$
\begin{gathered}
\frac{P a^{4}}{E h}=\frac{7-\mu}{3(1-\mu)} w^{3}, \\
\frac{3.58 w_{\mu}^{3}}{h^{3}}=\frac{P a^{4}}{E h^{4}} \quad(\text { при } \mu=0.3),
\end{gathered}
$$

где $P-$ приложенное избыточное давление; $a, h, \mu, w, E-$ соответственно радиус основания, толщина, коэффициент Пуассона, прогиб, модуль Юнга мембраны.

Другим часто используемым выражением является полученное из предположения о сферической форме 
мембраны под избыточным давлением [22,23] соотношение:

$$
P=\frac{4 \sigma_{0} h}{a^{2}} w+\frac{8 E h}{3(1-\mu) a^{4}} w^{3},
$$

где $\sigma_{0}-$ механическое напряжение в мембране без приложенного избыточного давления.

Также используется [41-45]:

$$
P=C_{0} \frac{E h^{3}}{(1-\mu) a^{4}} w+C_{1} \frac{\sigma_{0} h}{a^{2}} w+C_{2} \frac{E h}{(1-\mu) a^{4}} w^{3},
$$

где $C_{i}$ - постоянные коэффициенты, подбираемые эмпирически и зависящие от геометрии структуры (для круглых в плане мембран приближенно равны: $C_{0}=5.3$; $\left.C_{1}=4.4 ; C_{2}=2.6-3.4\right)$.

Отдельно стоит упомянуть методику определения начальных (остаточных [46-49]) механических напряжений в пленке на подложке (без приложения избыточного давления), также называемую пузырьковым методом [50-52]. В этом случае создается круглая область пленки, свободная от подложки. При сжимающем усилии пленка будет иметь начальный прогиб даже без приложенного давления и соответствующее начальное механическое напряжение можно определить в предположении о сферической форме образовавшейся мембраны с учетом равенства потенциальной энергии деформации мембраны $U$ и работы внешних сил $A$ на перемещение, вызванное этой деформацией [53]:

$$
\sigma_{0}=\frac{E w_{0}^{2}}{(1-\mu) a^{2}}
$$

где $w_{0}$ - начальный прогиб мембраны.

Однако на практике исходные формы мембран различны - они могут быть выгнуты в разные стороны относительно области закрепления, включать одновременно выпуклые и вогнутые области (рис. 3, $a, 4, a, 5$ ). Под воздействием избыточного давления мембрана может быть аналитически описана сегментом сферы лишь приближенно (в основном ближе к центру) [22,23,27,30,54].

C учетом представленных выше выражений или полученных на основе других подходов соотношений [36,54-65] определяются механические характеристики мембран. Таким образом, для анализа мембраны необходимо определить поданное давление $P$, eе прогиб $w$, радиус основания $a$ и толщину $h$.

\section{3. Определение начальных размеров и формы мембран}

Часто исходную форму мембраны можно описать усеченным конусом (рис. 3, $a, b$ ). При изготовлении мембран различного радиуса в одном технологическом процессе у мембран большого радиуса (рис. $3, a, b)$ меньшее основание усеченного конуса практически плоское, а у мембран малого радиуса (рис. $3, c, d)$ - нет.
Изменение формы мембраны также может быть вызвано особенностями ее размещения при проведении измерений. В частности, при размещении мембраны на держателе в используемом стенде [31] этот держатель зажимается сверху и снизу, что дополнительно сжимает мембрану и формирует однонаправленные складки (рис. $4, b, c)$. Поэтому стоит контролировать форму мембраны и степень ее прижатия [29]. Важно различать вызванные внешними воздействиями складки на мембране, и складки, являющиеся следствием внутренних механических напряжений освобожденной мембраны (склонны к радиальной симметрии).

Для наблюдения за геометрическими размерами и формой мембран были использованы: оптический профилометр Veeco Wyko NT 9300 и оптический микроскоп Nikon Eclipse L200N. Оптический профилометр использовался для определения размеров мембраны до и во время испытаний, оптический микроскоп - для первичной отбраковки. Используя проходящий и отраженный свет, режимы светлого и темного полей, микроскоп позволяет определять диаметры оснований усеченного конуса, контролировать полностью ли стравился непрозрачный кремний, анализировать дефекты, оценивать характер расположения складок при их наличии и др. [66].

Можно предположить, что радиус мембраны напрямую определяется используемым фотошаблоном. Однако диаметр отверстия в фотошаблоне может отличаться от реального получаемого диаметра мембраны. На рис. 5, $a$ представлен профиль поверхности $\operatorname{SiN}_{x}(0.13 \mu \mathrm{m}) / \mathrm{SiO}_{2}(0.5 \mu \mathrm{m}) / \operatorname{SiN}_{x}(0.13 \mu \mathrm{m}) / \mathrm{SiO}_{2}(0.5 \mu \mathrm{m})-$ мембраны, радиус отверстия которой предполагался равным $0.5 \mathrm{~mm}$, но реально составил $0.57 \mathrm{~mm}$. Поскольку при расчете модуля упругости $E$ значение радиуса основания мембраны $a$ возводится в четвертую степень, данное небольшое отклонение приводит к разнице более чем в полтора раза.

Для анализа толщины прозрачных пленок в микроэлектронике традиционно используется эллипсометрия [67-69]. Для определения толщин составляющих мембрану пленок часто используются результаты измерений слоев на пластине до вытравливания кремния с обратной стороны. Однако при реализации Бошпроцесса возможен перетрав мембраны и изменение еe толщины по диаметру. По этой причине необходимо контролировать толщины слоев непосредственно на мембране. Исследованы сформированные на одной пластине мембраны $p$-Si* $(0.8 \mu \mathrm{m}) / \mathrm{SiN}_{x}(0.13 \mu \mathrm{m}) /$ $\mathrm{SiO}_{2}(0.5 \mu \mathrm{m})$ (указаны предполагаемые толщины) различного диаметра (диаметры отверстий в фотошаблоне от 250 до $1000 \mu \mathrm{m})$. Обнаружено, что на всех мембранах толщина нижнего слоя $\left(\mathrm{SiO}_{2}\right)$ существенно меньше $(550 \mathrm{~nm}$ для мембран диаметром менее $500 \mu \mathrm{m}$ и 220-300 nm в центре для мембран диаметром более $500 \mu \mathrm{m})$, чем на кристалле без мембраны $(650 \mathrm{~nm})$. При этом на всех мембранах диаметром более $500 \mu \mathrm{m}$ толщина слоя $\mathrm{SiO}_{2}$ ближе к краю была на 60-80 nm 

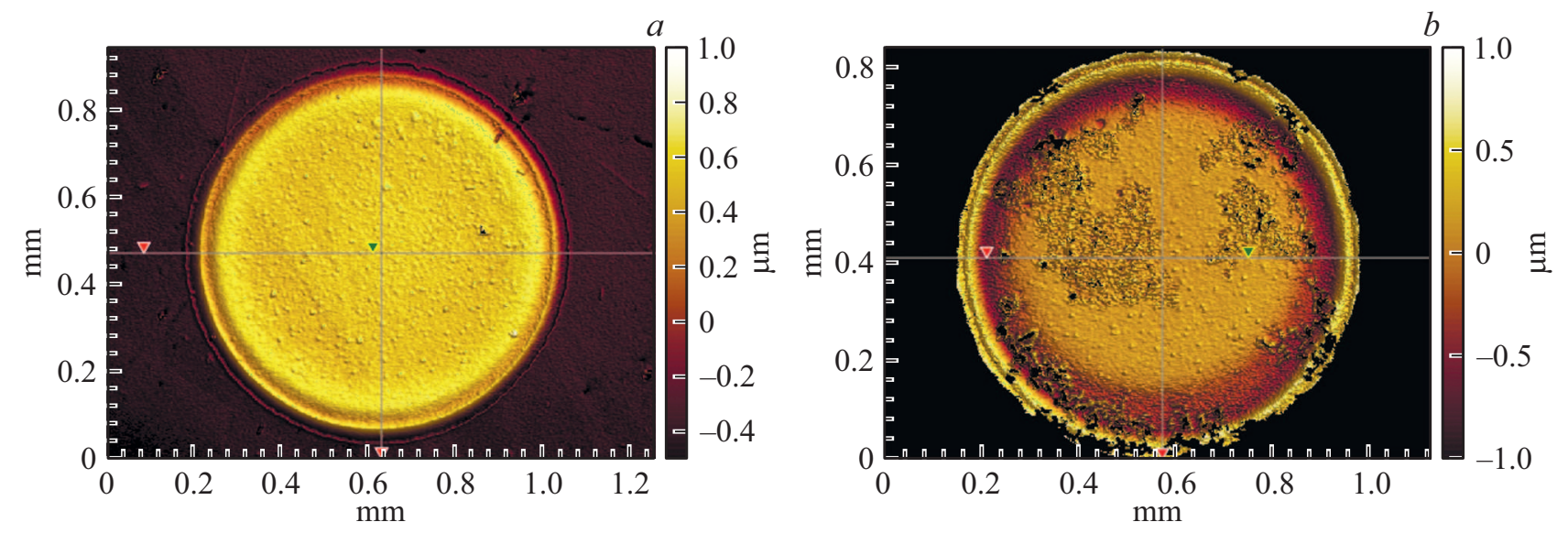

X profile: $\Delta X=0.5226 \mathrm{~mm} ; \Delta Z=0.9722 \mu \mathrm{m}$

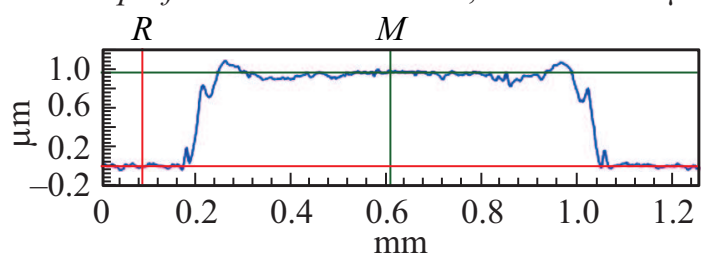

X profile: $\Delta X=0.5410 \mathrm{~mm} ; \Delta Z=0.7462 \mu \mathrm{m}$
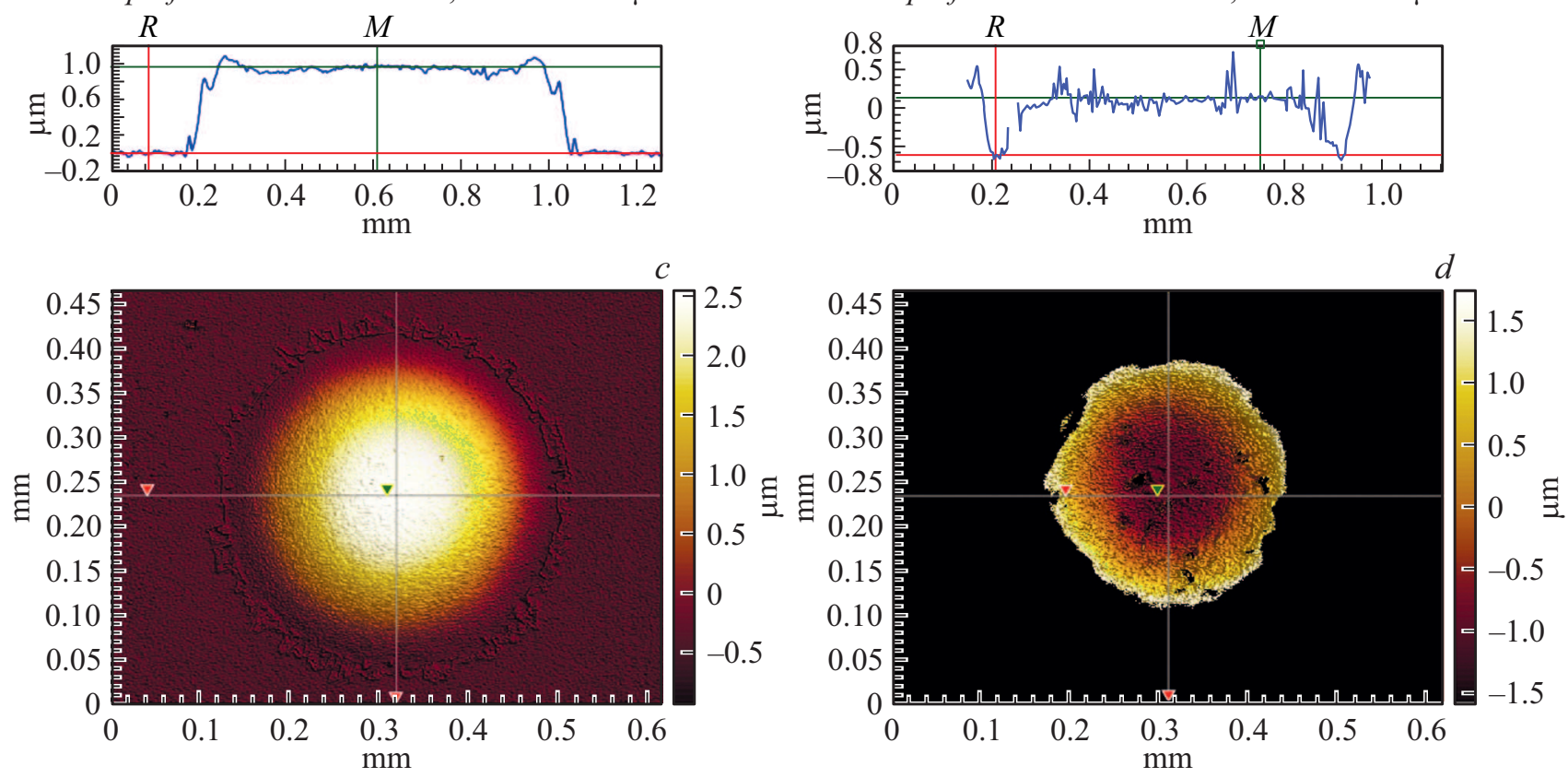

X profile: $\Delta X=0.2687 \mathrm{~mm} ; \Delta Z=3.0025 \mu \mathrm{m}$

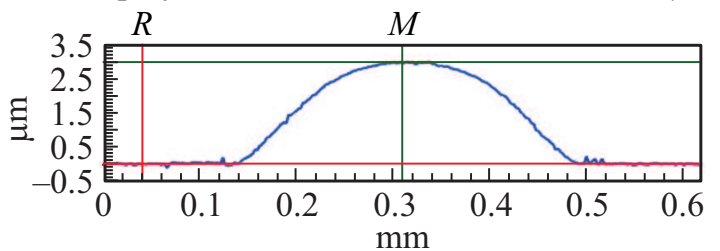

X profile: $\Delta X=0.1041 \mathrm{~mm} ; \Delta Z=-1.6884 \mu \mathrm{m}$

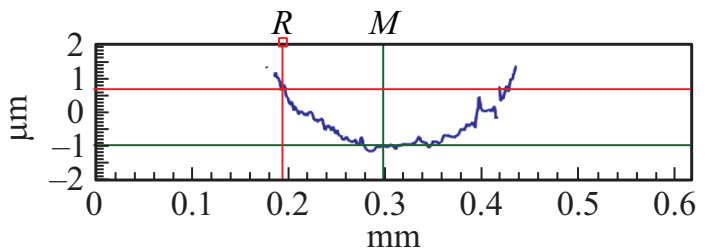

Рис. 3. Топографии и профили поверхности $p-\mathrm{Si}^{*} / \mathrm{SiN}_{x} / \mathrm{SiO}_{2}$-мембран: $a$ - мембрана большого диаметра, вид с лицевой стороны; $b$ - мембрана большого диаметра, вид с обратной стороны; $c-$ мембрана малого диаметра, вид с лицевой стороны; $d-$ мембрана малого диаметра, вид с обратной стороны.

больше, чем в центре. Проанализировав эти же мембраны методом рентгеновского энергодисперсионного микроанализа (PMA) [58,59], было обнаружено, что на мембране диаметром менее $500 \mu \mathrm{m}$ в центре элементное содержание кислорода $(\mathrm{O})$ больше, чем ближе к краю; на мембранах диаметром более $500 \mu \mathrm{m}$ в центре кислорода меньше, чем ближе к краю. Таким образом, данные РМА согласуются с результатами спектральной эллипсометрии. Отдельно стоит отметить, что при ана- лизе топографии поверхности этих мембран с их обратной стороны на мембранах диаметром более $500 \mu \mathrm{m}$ наблюдался обратный прогиб (рис. $3, b, d$ ). При данных измерениях образцы свободно располагались на столе. Проведенные на установке MicroProf200 измерения, при которых образец не касался стола в области мембраны, показали такую же форму поверхности.

На данном примере показано, что определение формы и толщины мембран является непростой задачей: форма 

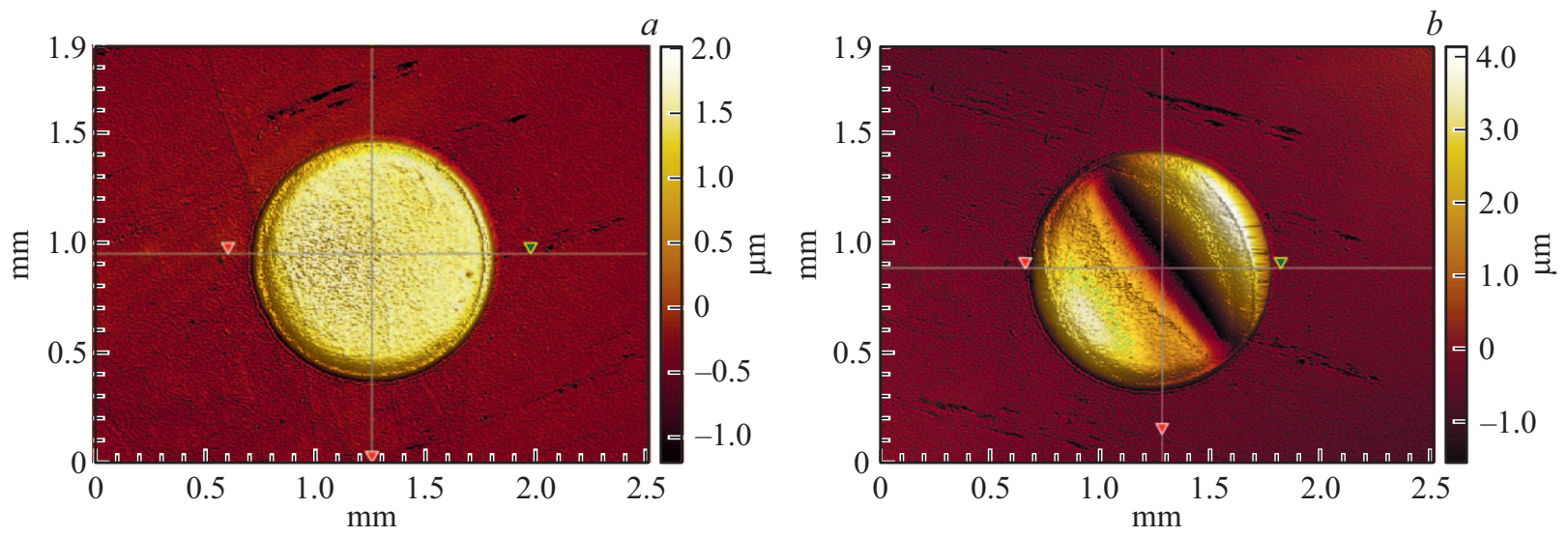

X profile: $\Delta X=1.3652 \mathrm{~mm} ; \Delta Z=-0.0905 \mu \mathrm{m}$

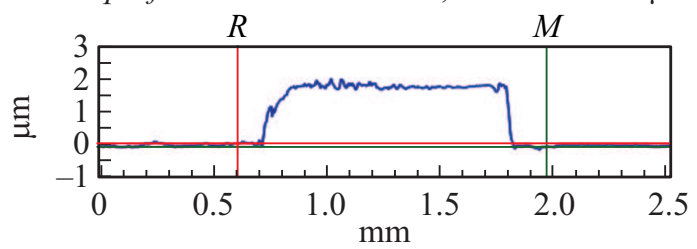

X profile: $\Delta X=1.1628 \mathrm{~mm} ; \Delta Z=-0.0124 \mu \mathrm{m}$
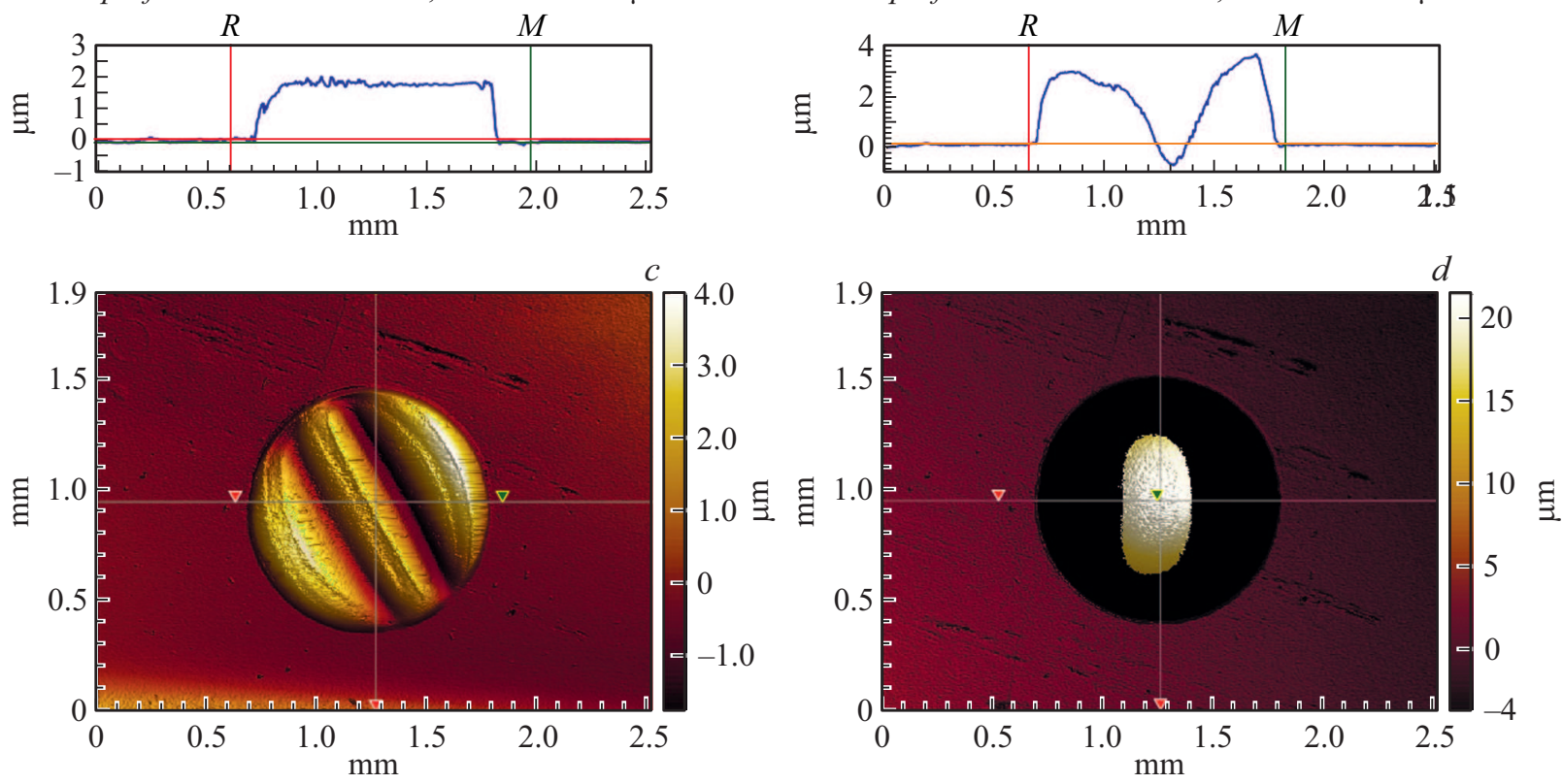

X profile: $\Delta X=1.2109 \mathrm{~mm} ; \Delta Z=0.0038 \mu \mathrm{m}$

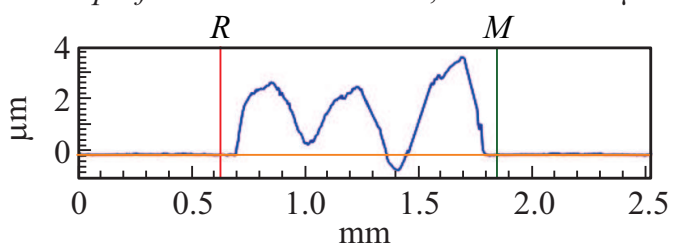

X profile: $\Delta X=0.7208 \mathrm{~mm} ; \Delta Z=22.0956 \mu \mathrm{m}$

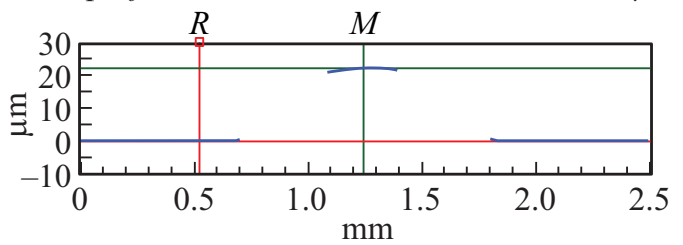

Рис. 4. Топографии и профили поверхности $p-\mathrm{Si}^{*} / \mathrm{SiN}_{x} / \mathrm{SiO}_{2}$-мембраны: $a-c-$ изменение формы мембраны по мере увеличения степени прижатия; $d-$ форма мембраны при избыточном давлении $P=0.8 \mathrm{~atm}$.

мембраны сложна и зависит от многих факторов, толщина мембраны неравномерна по ее площади, условия закрепления разнообразны.

\section{4. Влияние условий закрепления мембраны}

Еще один важный аспект, влияющий на напряженнодеформированное состояние мембран и предельное выдерживаемое ими давление (при превышении которого мембрана начинает разрушаться) - условия их за- крепления вдоль опорного контура. Идеальные модели закрепления (шарнирная, жесткая) не способны отразить реальные физико-механические параметры опорной зоны, поскольку в процессе травления свойства материалов и геометрическая форма окрестности опорной зоны формируется сложным способом (рис. 2), может содержать микротрещины и др.

Разрушение мембраны часто осуществляется по ее периметру в области закрепления, наибольшие механические напряжения зачастую наблюдаются по периметру мембраны в области закрепления [2,33,39]. В связи с этим, способом упрочнения данных мембран является 
$a$

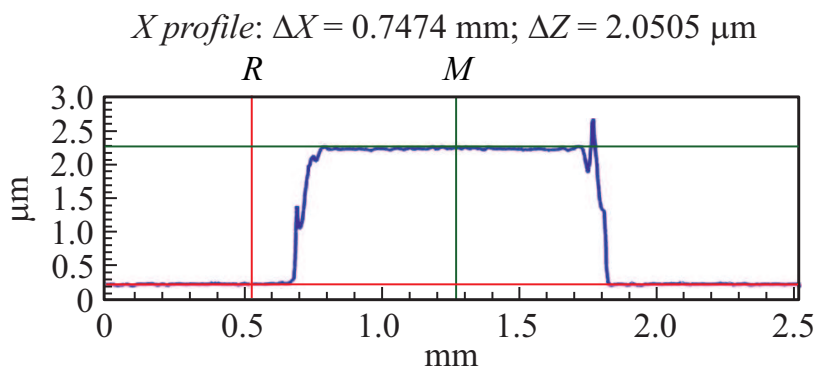

$b$

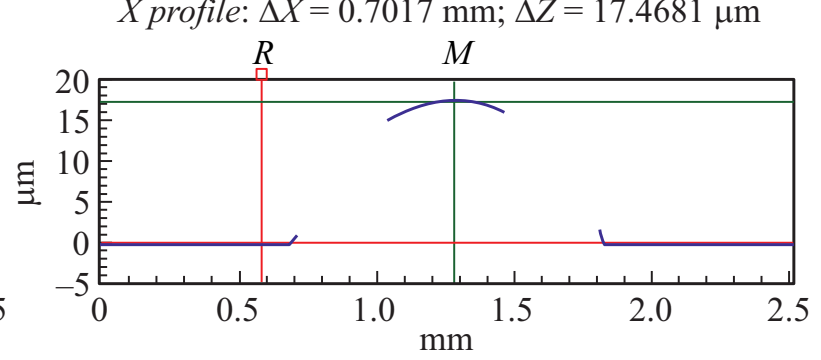

Рис. 5. Профили поверхности $\mathrm{SiN}_{x} / \mathrm{SiO}_{2} / \mathrm{SiN}_{x} / \mathrm{SiO}_{2}$-мембраны: $a$ - начальная форма мембраны (до подачи избыточного давления); $b-$ форма мембраны при избыточном давлении $P=0.4 \mathrm{~atm}$.

усиление области закрепления за счет использования консольных подкреплений (опор).

Поскольку аналитический расчет такого типа затруднен, было проведено численное моделирование. С целью оценки влияния параметров опоры на характеристики мембран проведено параметрическое моделирование в COMSOL Multiphysics (программное обеспечение для математического моделирования физических процессов, описывающихся дифференциальными уравнениями). Трехслойная круглая мембрана $\mathrm{Al}(0.8 \mu \mathrm{m}) / \mathrm{SiO}_{2}(0.6 \mu \mathrm{m}) / \mathrm{Al}(1.1 \mu \mathrm{m})$ радиусом основания $a=750 \mu \mathrm{m}$ [33] подвергалась деформации вследствие избыточного давления $P=0.3 \mathrm{MPa}$. Конструкция мембраны по всему ее периметру [70] была дополнена опорой из различных материалов: $\mathrm{SiO}_{2}$ или $\mathrm{Si}$. В разрезе эта кольцевая опора имела вид прямоугольного треугольника (рис. $6, a$ ).

Установлены зависимости влияния длины, материала и угла опоры на прогиб мембраны, интенсивность напряжений по Мизесу [35,39], смещение мембраны от координаты по радиусу (рис. $6, b-d$ ). Полученные результаты согласуются с физическими представлениями о деформировании мембран.

Подобные численные эксперименты обладают ценностью для выбора конкретных режимов в практических приложениях. Также они могут быть использованы при необходимости получения выдерживающих большое избыточное давление мембран, или же для определения корректирующих (поправочных) коэффициентов при анализе мембран со сложным закреплением по стандартным выражениям наподобие (1)-(4).

\section{5. Поведение мембраны сложной формы при подаче избыточного давления}

При увеличении избыточного давления форма мембраны постепенно становится близка к сегменту сферы (рис. $4, d$ ). В случае если мембрана изначально расположена выше уровня подложки и подобна усеченному конусу (рис. 4,a), конус постепенно переходит в подобную сегменту сферы форму (рис. 4, $d$ ). В случае если мембрана имеет сложную форму (рис. $4, b, c)$, она также постепенно становится выпуклым куполом. При этом величина прогиба одной и той же мембраны при ее испытаниях в случае разного уровня сжатия при закреплении (рис. $4, a-c$ ) является одинаковой (рис. $4, d$ ). В случае если мембрана изначально была расположена ниже уровня области закрепления (выгнута в обратную сторону), она вначале немного прогибается вверх, а затем с определенного давления резко меняет положение и также становится подобна выгнутому вверх сегменту сферы, т.е. ведет себя подобно хлопающим мембранам [62,63,71].

Многочисленные эксперименты по анализу зависимости прогиба от приложенного избыточного давления (графики, подобные рис. 7) показали, что эти деформации можно считать упругими: несколько проходов постепенного увеличения и уменьшения давления на мембрану соответствуют одной и той же графической зависимости $[31,32]$. Однако при этом в случае сброса давления в ноль одни мембраны принимают начальную форму до подачи избыточного давления, а другие нет. Первый случай, вероятно, связан с наличием в мембране существенных начальных механических напряжений (в том числе вызванных закреплением мембраны (рис. 4)), которые остались и после снятия избыточного давления и привели к оптимальной для мембраны форме. Второй случай предположительно наблюдается у достаточно свободных мембран, форма которых определяется небольшими возмущениями.

Наиболее часто при разрушении мембраны происходит полный ее отрыв от подложки $[2,70,71]$, при котором остается идеально ровное отверстие (рис. 8, $a$ ). Однако в общем случае могут наблюдаться разные формы этого отверстия (рис. 8).

\section{6. Расчет механических характеристик с учетом наличия начального прогиба}

Представляет интерес адаптация методик определения механических характеристик $((1)-(4))$ для имеющих начальный прогиб мембран. 

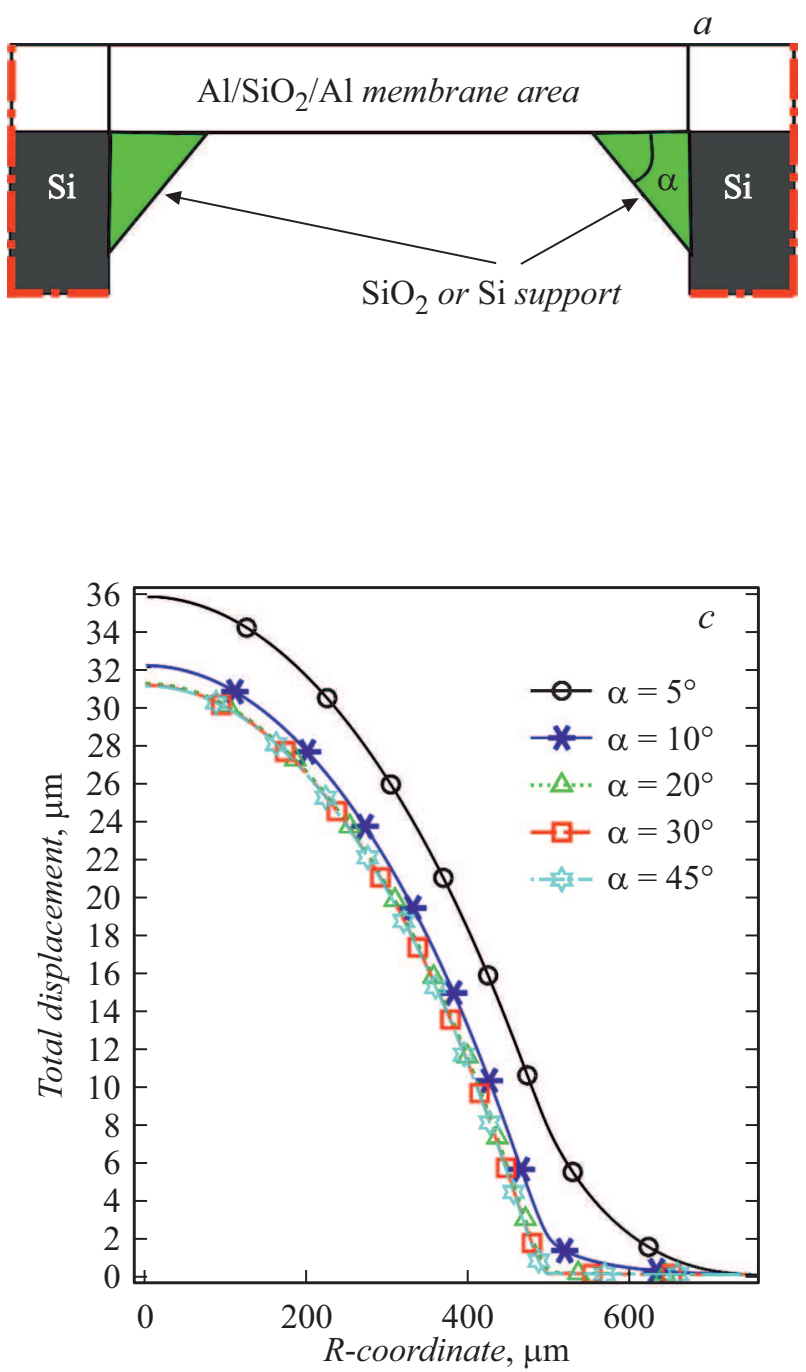
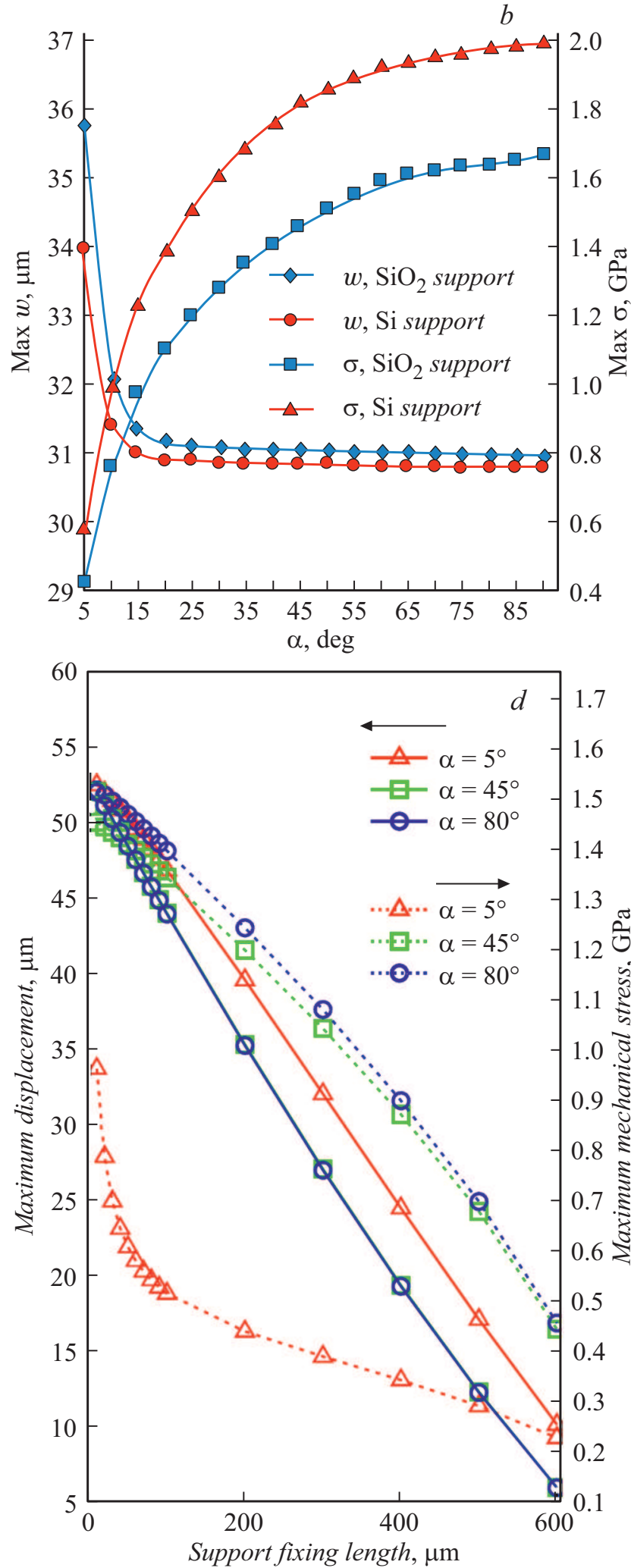

Рис. 6. Влияние параметров опоры на поведение мембраны: $a$ - схематичное изображение разреза $\mathrm{Al} / \mathrm{SiO}_{2} / \mathrm{Al}-\mathrm{Meмбраны} \mathrm{и} \mathrm{опоры;}$ $b$ - зависимость максимального прогиба и максимальной интенсивности напряжений по Мизесу от угла опоры $\alpha$ и ее материала (для фиксированной длины соприкосновения $250 \mu \mathrm{m}) ; c$ - величина смещения мембраны от координаты по радиусу для различных углов опоры $\left(\right.$ из $\left.\mathrm{SiO}_{2}\right) ; d-$ зависимость максимального прогиба и максимальной интенсивности напряжений по Мизесу от длины соприкосновения опоры и мембраны (при фиксированных углах опоры $\alpha=5,45,80^{\circ}$ ). 


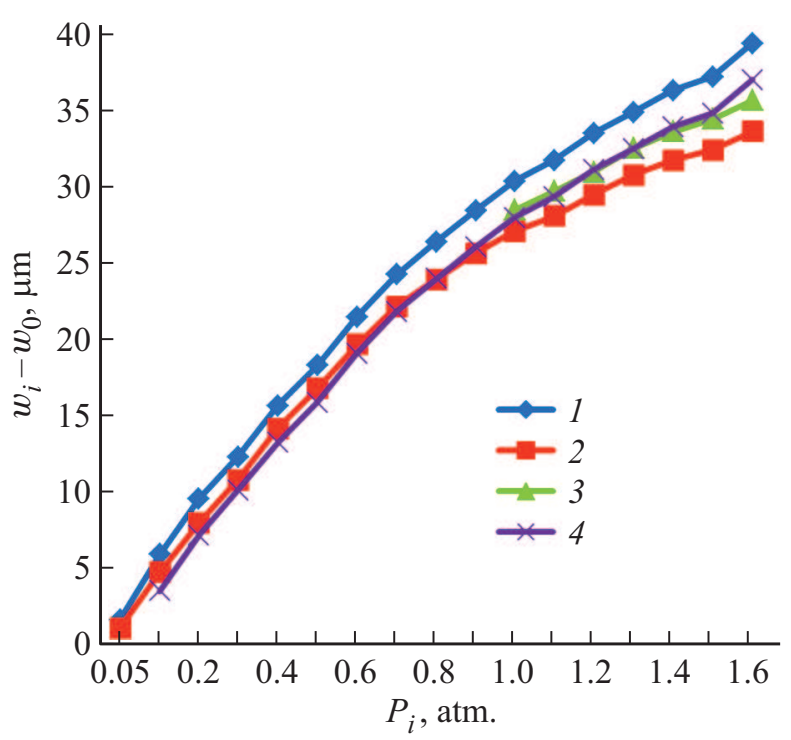

Рис. 7. Зависимость изменения прогиба $\left(w_{i}-w_{0}\right)$ от избыточного давления $P_{i}$ для $\mathrm{SiN}_{x} / \mathrm{SiO}_{2} / \mathrm{SiN}_{x} / \mathrm{SiO}_{2}$-мембраны: 1 (ромбы) $-w_{0}$ и $w_{i}$ определены по профилям поверхности, $w_{0}=2 \mu \mathrm{m} ; 2$ (квадраты) - $w_{0}$ и $w_{i}$ рассчитаны из (7), $w_{0}=4.3 \mu \mathrm{m} ; 3$ (треугольники) $-w_{0}$ и $w_{i}$ рассчитаны из (7), недостающие данные определялись по авторской методике, $w_{0}=4.3 \mu \mathrm{m} ; 4$ (кресты) - $w_{0}$ рассчитан из (7), $w_{i}-$ определены по профилям поверхности, $w_{0}=4.3 \mu \mathrm{m}$.

По мере увеличения избыточного давления форма мембраны становится подобна сегменту сферы (рис. 3,5), высота которого (соответствующая прогибу мембраны) также постепенно увеличивается. Аналогичным образом увеличивается и площадь поверхности мембраны. Детальный учет реальной формы мембраны сложен для аналитического анализа. Для определения механических характеристик мембраны важно изменение по мере подачи избыточного давления прогиба мембраны в области упругих деформаций. Поэтому для дальнейших расчетов будет использовано соответствие реальной площади поверхности мембраны - площади модельной поверхности сферического сегмента. Таким образом, для анализа изменения формы мембраны от избыточного давления можно использовать изменение площади мембраны или изменение высоты модельного сферического сегмента. Для этого необходимо рассчитать начальную площадь поверхности мембраны, а затем вычислить начальный „эффективный прогиб“ - высоту модельного сферического сегмента.

В случае достаточно простой формы мембраны (рис. $5, a$ ) ее площадь поверхности можно рассчитать аналитически. Для подобной усеченному конусу формы мембраны:

$$
S=\pi \frac{d^{2}}{4}+\pi \sqrt{H^{2}+\left(\frac{D}{2}-\frac{d}{2}\right)^{2}}\left(\frac{D}{2}+\frac{d}{2}\right),
$$

где $S$ - площадь поверхности мембраны, $d$ - диаметр меньшего основания, $D$ - диаметр большего основания, H - высота.

В случае более сложной формы поверхности, а также при необходимости автоматизации измерений расчет проводится численно посредством наложения треугольной сетки. Обрабатывается массив экспериментальных данных топографии поверхности $(X, Y, Z)$. Для этого необходимо определить область расположения мембраны [28] и просуммировать элементарные площади всех треугольников - ячеек сетки.

Соответствующий „эффективный прогиб“ $w_{\text {eff мем- }}$ браны вычисляется из соотношения [29]:

$$
w_{\mathrm{eff}}=\sqrt{\left(S-S_{0}\right) / \pi},
$$

где $S$ - площадь поверхности мембраны, $S_{0}$ - площадь ее основания, $S_{0}=\pi a^{2}$.

При численном расчете площади поверхности мембраны посредством наложения сетки значение $S_{0}$ также стоит рассчитывать на основе массива данных $(X, Y, Z)$ и определенной области расположения мембраны.

Выражение (7) применимо только для круглых в плане мембран. Однако его получение для другой формы отверстий осуществляется подобным образом.

При анализе осуществляется расчет „эффективного прогиба“ мембраны по мере увеличения избыточного давления. После того как форма мембраны станет подобна сегменту сферы, значение „эффективного прогиба“ будет совпадать с измеренным по профилю.

Для анализа зависимости между прогибом мембраны и приложенным избыточным давлением стоит использовать разницу между текущим прогибом мембраны $w_{i}$ при наличии избыточного давления $P_{i}$ и начальным „эффективным прогибом“ $w_{0}$ при отсутствии приложенного избыточного давления (из соотношения (7)). При этом расчет механических характеристик стоит проводить на нелинейном участке зависимости $w(P)$ вблизи высоких давлений.

На рис. 7 показана зависимость изменения прогиба $\left(w_{i}-w_{0}\right)$ по мере подачи избыточного давления для $\mathrm{SiN}_{x}(0.13 \mu \mathrm{m}) / \mathrm{SiO}_{2}(0.5 \mu \mathrm{m}) / \mathrm{SiN}_{x}(0.13 \mu \mathrm{m}) / \mathrm{SiO}_{2}(0.5 \mu \mathrm{m})-$ мембраны $[29,32]$, предельное выдерживаемое давление $1.6 \mathrm{~atm}$. Начальная форма поверхности представляла собой усеченный конус с диаметром верхнего основания $d=0.95 \mathrm{~mm}$, нижнего основания $D=1.1431 \mathrm{~mm}$, высотой $H=2 \mu \mathrm{m}$ (рис. $5, a$ ).

Определенный из площади поверхности начальный „эффективный прогиб“ составил $4.42 \mu \mathrm{m}$ при расчете по аналитическому выражению (6) и $4.30 \mu \mathrm{m}$ при расчете посредством наложения треугольной сетки. С учетом точности проведения измерений и вычислений полученные данные сопоставимы.

Рассчитанная по способу 2 зависимость показывают заниженные значения прогибов вблизи высоких давлений („квадраты“, рис. 7). Это вызвано ограничениями 


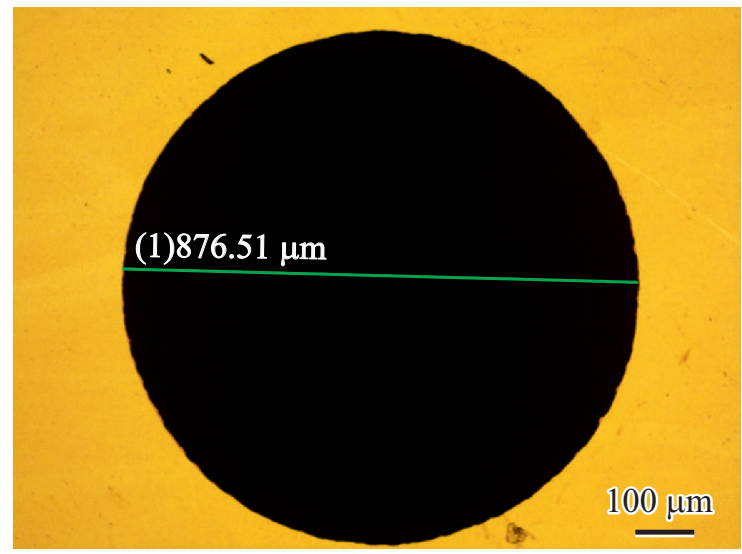

$b$

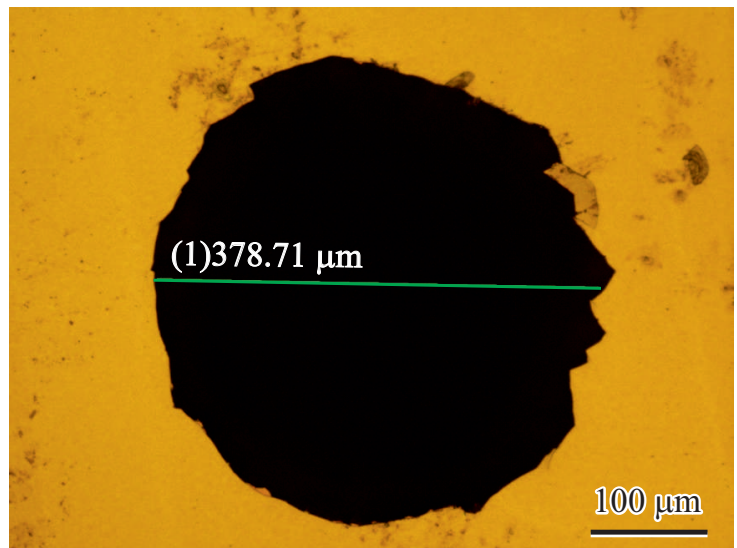

Рис. 8. Вид отверстий, полученный на оптическом микроскопе Nikon Eclipse L200N после отрыва мембран: $a$ - ровное отверстие (испытания мембраны с рис. $3, a, b$, отрыв при $P=2.5 \mathrm{~atm}) ; b$ - отверстие с рваными краями (испытания мембраны с рис. $3, c, d$, отрыв при $P=4.5 \mathrm{~atm})$

используемого метода измерений - отсутствием части данных о топографии поверхности (рис. 5,b). Для расчета площади поверхности мембраны производится восстановление промежуточных данных с помощью встроенного программного обеспечения. Однако при высоких давлениях также отсутствуют сведения и на самых краях расположения мембраны, что затрудняет восстановление ее формы - вместо резкого перехода (подобного рис. 5,b) наблюдается плавный выход на купол. Поэтому была разработана программа для восстановления данных, позволяющая получить искомую форму мембраны и затем рассчитать $w_{i}$ (,треугольники“, рис. 7) в предположении наличия такого резкого перехода.

Зависимости на рис. 7, отображенные треугольниками и крестами, фактически совпадают, что показывает правомерность описанной методики и алгоритмов расчета.

Приведем примеры расчета модуля эффективной упругости многослойной мембраны - величины, соответствующей комплексу составляющих мембрану слоев и определенной по выражениям (1)-(4), т. е. без явного аналитического учета особенностей, вызванные малой толщиной структур. Для определения предполагаемого модуля упругости многослойной структуры использовалось выражение [32,45]:

$$
E_{\text {structure }}=\frac{E_{\text {layer } 1} h_{\text {layer } 1}+\ldots+E_{\text {layer } N} h_{\text {layer } N}}{h_{\text {layer } 1}+\ldots+h_{\text {layer } N}} .
$$

Для рассматриваемой $\mathrm{SiN}_{x} / \mathrm{SiO}_{2} / \mathrm{SiN}_{x} / \mathrm{SiO}_{2}$-мембраны $\mu=0.214 \quad$ (поскольку $\left.\mu\left(\mathrm{SiO}_{2}\right)=0.2, \mu\left(\mathrm{SiN}_{x}\right)=0.27\right)$, расчет по аналогии с (8). В соответствии с (1) модуль эффективный упругости многослойной мембраны составил $E=110 \mathrm{GPa}$ (расчет проводился при $P=0.14 \mathrm{MPa}$, $\left.w=\left(w_{i}-w_{0}\right)=33.5 \mu \mathrm{m}, \quad a=0.57155 \mathrm{~mm}\right)$. Полученный результат сопоставим с предполагаемым значением модуля упругости данной мембраны по (8). Однако, поскольку значение начального прогиба невелико, его влияние на численный результат расчета модуля упругости мало [32].

Более показателен пример определения модуля эффективной упругости многослойной мембраны для структуры с существенным начальным прогибом. Продемонстрируем расчет на примере мембраны $\mathrm{Al}(0.8 \mu \mathrm{m}) / \mathrm{SiO}_{2}(0.6 \mu \mathrm{m}) / \mathrm{Al}(1.1 \mu \mathrm{m}) \quad[29,32]$, предельное выдерживаемое давление $5.8 \mathrm{~atm}$. Мембрана $\mathrm{Al} / \mathrm{SiO}_{2} / \mathrm{Al}$ до подачи избыточного давления имела близкую к сферическому сегменту форму, $w_{0}=30 \mu \mathrm{m}, a=0.5264 \mathrm{~mm}$. При $P_{i}=0.24 \mathrm{MPa}, w_{i}=60 \mu \mathrm{m}, w=\left(w_{i}-w_{0}\right)=30 \mu \mathrm{m}$. Поскольку $\mu(\mathrm{Al})=0.34, \mu\left(\mathrm{SiO}_{2}\right)=0.2$, для данной мембраны $\mu=0.3$. В соответствии с (2) модуль эффективный упругости многослойной мембраны составил $E=76 \mathrm{GPa}$. Полученный результат сопоставим со значением модуля упругости для составляющих мембрану материалов - алюминия и оксида кремния.

Таким образом, с учетом некоторых указанных выше изменений [29] выражения, подобные (1)-(4), могут использоваться для анализа мембран с начальным прогибом.

\section{Заключение}

Описаны экспериментально наблюдаемые особенности тонкопленочных мембран, сформированных над круглыми отверстиями в кремниевых подложках с помощью Бош-процесса травления. Указана специфика этого технологического процесса, приводящая к неточному соответствию получаемых геометрических размеров мембран и условий закрепления вдоль опорного контура предполагаемым.

Показана необходимость точного определения геометрических размеров мембраны для корректного расчета механических характеристик посредством анализа зависимости прогиба мембраны w от поданного избыточного давления $P$. 
Диаметр мембран определялся посредством оптической профилометрии и оптической микроскопии на примере $\operatorname{SiN}_{x}(0.13 \mu \mathrm{m}) / \mathrm{SiO}_{2}(0.5 \mu \mathrm{m}) / \mathrm{SiN}_{x}(0.13 \mu \mathrm{m}) /$ $\mathrm{SiO}_{2}(0.5 \mu \mathrm{m})$-мембран.

Определение толщин прозрачных слоев мембраны показано на примере $p-\mathrm{Si}^{*}(0.8 \mu \mathrm{m}) / \mathrm{SiN}_{x}(0.13 \mu \mathrm{m}) /$ $\mathrm{SiO}_{2}(0.5 \mu \mathrm{m})$-мембран (предполагаемые толщины) диаметром 250-1000 $\mu \mathrm{m}$. По данным спектральной эллипсометрии обнаружены радиальная неоднородность толщины нижнего слоя $\left(\mathrm{SiO}_{2}\right)$ и различие в толщинах этого слоя на мембранах разного диаметра: для диаметра более $500 \mu \mathrm{m}$ толщина составила $220-300 \mathrm{~nm}$, в центре мембраны для диаметра менее $500 \mu \mathrm{m}$ толщина составила $550 \mathrm{~nm}$, на области кристалла без мембраны $650 \mathrm{~nm}$.

Показано, что в связи с напряженным состоянием исходных пленок, реальная форма сформированных мембран не плоская и не сегмент сферы. Во многих случаях форма мембраны подобна усеченному конусу. На форму мембраны влияют внешние воздействия (особенности размещения при проведении измерений).

Описаны особенности изменения формы мембраны при подаче на нее избыточного давления и при его сбросе. При увеличении поданного давления первоначально подобная усеченному конусу мембрана, как и мембрана более сложной формы, постепенно принимает подобную сегменту сферы форму. Деформации являются упругими.

Путем параметрического моделирования в COMSOL Multiphysics установлены зависимости влияния длины, материала и угла опоры на поведение $\mathrm{Al}(0.8 \mu \mathrm{m}) /$ $\mathrm{SiO}_{2}(0.6 \mu \mathrm{m}) / \mathrm{Al}(1.1 \mu \mathrm{m})$-мембраны: ее прогиб, смещение от координаты по радиусу, интенсивность напряжений по Мизесу. Полученные результаты согласуются с физическими представлениями о деформировании мембран.

В соответствии с разработанной методикой измерений и расчета механических характеристик мембран эффективный модуль упругости многослойной структуры $\mathrm{SiN}_{x}(0.13 \mu \mathrm{m}) / \mathrm{SiO}_{2}(0.5 \mu \mathrm{m}) / \mathrm{SiN}_{x}(0.13 \mu \mathrm{m}) / \mathrm{SiO}_{2}(0.5 \mu \mathrm{m})$ составил $110 \mathrm{GPa}$, многослойной структуры $\mathrm{Al}(0.8 \mu \mathrm{m}) /$ $\mathrm{SiO}_{2}(0.6 \mu \mathrm{m}) / \mathrm{Al}(1.1 \mu \mathrm{m})-76 \mathrm{GPa}$.

Дальнейшие исследования предполагают учет описанных в настоящей работе особенностей тонкопленочных мембран и использование описанных методик идентификации их параметров для развития математических моделей прогнозирования поведения микроструктур при различных физических и механических воздействиях.

\section{Благодарности}

Авторы благодарны Э. Рзаеву (АО „ЗНТЦ“ ) за проведение изменений на MicroProf200 и Е.Ю. Юрасовой (МИЭТ) за проведение исследований методом рентгеновского энергодисперсионного микроанализа.

\section{Финансирование работы}

Работа выполнена с использованием оборудования ЦКП „Микросистемная техника и электронная компонентная база“ (МИЭТ) при финансовой поддержке Минобрнауки России (№ 075-03-2020-216, 0719-20200017, мнемокод FSMR-2020-0017).

\section{Конфликт интересов}

Авторы заявляют, что у них нет конфликта интересов.

\section{Список литературы}

[1] Н.А. Дюжев, М.А. Махиборода, Р.Ю. Преображенский, Г.Д. Демин, Э.Е. Гусев, А.А. Дедкова. Поверхность. Рентгеновские, синхротронные и нейтронные исследования, 4, 64 (2017). DOI: 10.7868/S0207352817040060 [N.A. Djuzhev, M.A. Makhiboroda, R.Y. Preobrazhensky, G.D. Demin, E.E. Gusev, A.A. Dedkova. J. Surf. Investigation: X-ray, Synchrotron and Neutron Techniq., 11 (2), 443 (2017). DOI: $10.1134 / \mathrm{S} 1027451017020239]$

[2] Н.А. Дюжев, Е.Э. Гусев, А.А. Дедкова, Д.А. Товарнов, M.А. Махиборода. ЖТФ, 90 (11), 1838 (2020). DOI: $10.21883 /$ JTF.2020.11.49971.107-20 [N.A. Djuzhev, E.E. Gusev, A.A. Dedkova, D.A. Tovarnov, M.A. Makhiboroda. Tech. Phys., 65(11), 1755 (2020). DOI: $10.1134 / \mathrm{S} 1063784220110055]$

[3] A. Nazarov, I. Abdulhalim. Sensors and Actuators A: Physical, 257, 113 (2017). DOI: 10.1016/j.sna.2017.02.020

[4] C. Zorman. Material Aspects of Micro- and Nanoelectromechanical Systems (Springer Handbook of Nanotechnology, Springer-Verlag, Berlin 2007)

[5] Н.А. Дюжев, Е.Э. Гусев, Т.А. Грязнева, А.А. Дедкова, Д.А. Дронова, В.Ю. Киреев, Е.П. Кириленко, Д.М. Мигунов, Д.В. Новиков, Н.Н. Патюков, А.А. Преснухина, А.Д. Бакун, Д.С. Ермаков Российские нанотехнологии, 12(7-8), 97 (2017). [N.A. Dyuzhev, E.E. Gusev, T.A. Gryazneva, A.A. Dedkova, D.A. Dronova, V.Yu. Kireev, E.P. Kirilenko, D.M. Migunov, D.V. Novikov, N.N. Patyukov, A.A. Presnukhina, A.D. Bakun, D.S. Ermakov, Nanotechnologies in Russia, $12(7-8), 426$ (2017). DOI: $10.1134 /$ S1995078017040073]

[6] P. Rosakis. Networks and Heterogeneous Media, 9(3), 453 (2014). DOI: $10.3934 / \mathrm{nhm} .2014 .9 .453$

[7] M. Kardar, G. Parisi, I.-Ch. Zhang. Phys. Rev. Lett., 56 (9), 889 (1986). DOI: 10.1103/PhysRevLett.56.889

[8] J. Braun, B. Schmidt. Calc. Var., 55(5), 125 (2016). DOI: $10.1007 / \mathrm{s} 00526-016-1048-\mathrm{x}$

[9] M.E. Gurtin, A.I. Murdoch. Archive for Rational Mechanics and Analysis, 57 (4), 291 (1975). DOI: 10.1007/bf00261375

[10] S. Majaniemi, T. AlaNissila, J. Krug. Phys. Rev. B, 53 (12), 8071 (1996).

[11] R. Molzon, C.S. Man. J. Elasticity, 20 (3), 181 (1988).

[12] B. Schmidt. Networks and Heterogeneous Media, 4 (4), 789 (2009).

[13] C.Q. Ru. Science China-Physics Mechanics \& Astronomy, 53 (3), 536 (2010). DOI: 10.1007/s11433-010-0144-8

[14] C.Q. Ru. Continuum Mech. Thermodyn., 28(1-2), 263 (2016). DOI: $10.1007 / \mathrm{s} 00161-015-0422-9$

[15] R. Shuttleworth. Proc. Phys. Soc. A, 63, 444 (1950). 
[16] F. Theil. ESAIM: M2AN, 45 (5), 873 (2011). DOI: $10.1051 / \mathrm{m} 2 \mathrm{an} / 2010106$

[17] E. Orowan. Proc. Roy. Soc. Lond. A, 316, 473 (1970).

[18] C.-Y. Hui, A. Jagota. Langmuir, 29 (36), 11310 (2013). DOI: $10.1021 / 1 a 400937 \mathrm{r}$

[19] С.А. Лычев, Т.Н. Лычева, А.В. Манжиров. Известия РАН. Механика твердого тела, 2, 199 (2011) [S.A. Lychev, A.V. Manzhirov, T.N. Lycheva. Mechanics of Solids, 46 (2), 325 (2011). DOI: 10.3103/S002565441102021X]

[20] S. Lychev, K. Koifman. Acta Mechan., 230 (11), 3989 (2019). DOI: 10.1007/s00707-019-02399-7

[21] S. Lychev. ZAMM Zeitschrift fur Angewandte Mathematik Mechanik, 94 (1-2), 118 (2014). DOI: $10.1002 /$ zamm.201200231

[22] A. Degen, J. Voigt, B. Sossna, F. Shi, I.W. Rangelow. Proceedings SPIE, 3996, 97 (2000).

[23] M.K. Small, W.D. Nix. J. Mater. Res., 7 (6), 1553 (1992).

[24] В.Ю. Киреев. Нанотехнологии в микроэлектронике. Нанолитограбия - процессы и оборудование (Издательский дом „Интеллект“, Долгопрудный, 2016)

[25] В.С. Сергеев, О.А. Кузнецов, Н.П. Захаров, В.А. Летягин. Напряжения и дебормации в элементах микросхем (Радио и связь, М., 1987)

[26] Г.П. Егоров. Диссертация на соискание ученой степени кандидата физико-математических наук „Механические напряжения в металлических пленках при магнетронном осаждении“ (НИЯУ „МИФИ“, М., 2018)

[27] С.Ф. Сенько, В.А. Зеленин. Приборы и методы измерений, 9 (3), 254 (2018). DOI: $10.21122 / 2220-9506-2018-9-3-254-262$

[28] А.А. Дедкова, Н.А. Дюжев, Е.Э. Гусев, M.Ю. Штерн. Дефектоскопия, 5, 52 (2020). DOI: $10.31857 / \mathrm{S} 0130308220050073$ [A.A. Dedkova, N.A. Dyuzhev, E.E. Gusev, M.Yu. Shtern. Rus. J. Nondestructive Testing, 56 (5), 452 (2020). DOI: $10.1134 / \mathrm{S} 1061830920050046]$

[29] А.А. Дедкова, В.Ю. Киреев, В.А. Беспалов, А.Л. Переверзев. Заявка на изобретение РФ 2021106059.

[30] F.R. Brotzen. Intern. Mater. Rev., 39 (1), 24045 (1994).

[31] Е.Э. Гусев, А.А. Дедкова, Н.А. Дюжев. Наноиндустрия, S (82), 538 (2018). DOI: $10.22184 / 1993-8578.2018 .82 .538 .541$

[32] А.А. Дедкова, Е.Э. Гусев, В.С. Ларионов, Н.А. Дюжев. Третий междисциплинарный молодежный научный форум с международным участием „Новые материалы“. Сборник материалов, 251 (2017).

[33] A.A. Dedkova, P.Yu. Glagolev, G.D. Demin, E.E. Gusev, P.A. Skvortsov. 2020 IEEE Conf. Rus. Young Researchers in Electrical and Electronic Engineering (EIConRus), 2288 (2020). DOI: 10.1109/EIConRus49466.2020.9039289

[34] E.I. Bromley, J.N. Randall, D.C. Flanders, R.W. Mountion. J. Vac. Sci. Technol. B, 1 (4), 1364 (1983).

[35] А.И. Козлов. Исследование и разработка мембранных тензопреобразователей давления. Диссертация на соискание ученой степени кандидата технических наук. (УлГТУ, Ульяновск, 2014), 113 с.

[36] Н.М. Якупов, В.Н. Куприянов, Р.Г. Нуруллин, С.Н. Якупов. Патент РФ 2387973

[37] J. Yang, W. Zhou, F. Yang. Patient CN101520385

[38] А.Н. Гоц. Численные методы расчета в энергомашиностроении. Учебное пособие в двух частях. Часть 2 (Изд-во Владимирского гос. ун-та, Владимир, 2010)
[39] Л.Е. Андреева. Упругие элементы приборов (Машгиз, M., 1962)

[40] С.П. Тимошенко, С. Войновский-Кригер. Пластинки и оболочки (Наука, М., 1966)

[41] А.А. Саченков. Цикл лекций по теории пластин и оболочек: учебное пособие (Казанский университет, Казань, 2018)

[42] А.В. Корляков. Нано- и микросистемная техника, 8, 17 (2007).

[43] Е.Д. Хребтова. Разработка методики измерения механических характеристик мембранных элементов. Выпускная квалификационная работа магистра по направлению 28.04.01 (СПбГЭТУ „ЛЭТИ“, СПб., 2017), $99 \mathrm{c}$.

[44] И.А. Вавилин. Разработка лабораторного стенда для определения прогиба микромеханических мембран. Выпускная квалибикационная работа бакалавра по направлению 28.03.01 (СПбГЭТУ „ЛЭТИ“, СПб., 2017)

[45] О.Н. Асташенкова. Физико-технологические основы управления механическими напряжениями в тонкопленочных композициях микромеханики. Диссертация на соискание ученой степени к.т.н. по специальности 05.27.06 (СПбГЭУ „ЛЭТИ“, СПб., 2015), 143 с.

[46] И.А. Биргер. Остаточные напряжения (Красный печатник, Л., 1963)

[47] P. Waters. Stress Analysis and Mechanical Characterization of Thin Films for Microelectronics and MEMS Applications. A dissertation submitted in partial fulfillment of the requirements for the degree of Doctor of Philosophy 215 c., Department of Mechanical Engineering College of Engineering University of South Florida, 2008

[48] F. Fachin, S.A. Nikles, J. Dugundji, B.L. Wardle. J. Micromech. Microeng, 21, 095017 (2011). DOI: $10.1088 / 0960-1317 / 21 / 9 / 095017$

[49] А.Н. Кривошеева, А.В. Корляков, В.В. Лучинин, А.М. Ефременко. Патент РФ 2327252

[50] Механические напряжения в тонких пленках (Реферативно-аналитический обзор). Выпуск 8 (798). Серия 2 „Полупроводниковые приборы“ (ЦНИИ „Электроника“, М., 1981)

[51] Под ред. Л. Майсела, Р. Глэнга. Технология тонких пленок (справочник) (Сов. радио, М., 1970) [Перс. с англ. М.И. Елинсона, Г.Г. Смолко, 1977]

[52] М.Е. Галкина. Внутренние напряжения в углеродных конденсатах, формируемых импульсным вакуумно-дуговым методом. Диссертация на соискание ученой степени к.ф.м.н., специальность 01.04.07 (Белгородский гос. ун-т, Белгород, 2005), 165 с.

[53] Электронный ресурс. И. Каримов. „Лекция 4. Пластины, мембраны“ Available: http://www.soprotmat.ru/ lectuprugost4.htm

[54] G. Machado, D. Favier, G. Chagnon. Experimental Mechanics, 52, 865 (2012). DOI: 10.1007/s11340-011-9571-3

[55] Н.К. Галимов, С.Н. Якупов. Строительная механика инженерных конструкций и сооружений, 4, 13 (2009).

[56] Н.М. Якупов, В.Н. Куприянов, С.Н. Якупов. Известия Казанского государственного архитектурно-строительного университета, 1 (9), 106 (2008).

[57] С.Н. Якупов. Известия РАН. Механика твердого тела, 3, 58 (2011).

[58] Н.М. Якупов, С.Н. Якупов. Строительная механика инженерных конструкций и сооружений, 1, 6 (2017). 
[59] Н.К. Галимов, С.Н. Якупов. Строительная механика инженерных конструкций и сооружений, 4, 74 (2012).

[60] Н.К. Галимов, С.Н. Якупов. Строительная механика инженерных конструкций и сооружений, 3, 73 (2008).

[61] T. Tsakalakos. Metallurgical and Protective Coatings, 75, 293 (1981).

[62] М.С. Ганеева, В.Е. Моисеева, 3.В. Скворцова. Ученые записки Казанского университета. Серия физикоматематические науки, 160 (4), 670 (2018).

[63] И.П. Гетман, М.И. Карякин, Г.О. Мостипан, И.А. Панфилов, Ю.А. Устинов. Известия вузов. Северо-кавказский регион. Естественные науки, 4, 24 (2011).

[64] S. Jianbing, L. Xiang, X. Sufang, W. Wenjia. Interna. J. Polymer Sci., 2017, 4183686 (2017).

DOI: $10.1155 / 2017 / 4183686$

[65] R.H. Plaut. Acta Mech., 202, 79 (2009). DOI: $10.1007 / \mathrm{s} 00707-008-0037-3$

[66] А.А. Дедкова, М.А. Махиборода. Наноструктуры. Математическая физика и моделирование, 20 (2), 41 (2020). DOI: $10.31145 / 2224-8412-2020-20-2-41-64$

[67] В.А. Швец, Е.В. Спесивцев, С.В. Рыхлицкий, Н.Н. Михайлов. Российские нанотехнологии, 4(2-4), 91 (2009). [V.A. Shvets, E.V. Spesivtsev, S.V. Rykhlitskii, N.N. Mikhailov. Nanotechnologies in Russia, 4 (3-4), 201 (2009). DOI: 10.1134/S1995078009030082]

[68] Под ред. А. Зандерны. Методы анализа поверхностей (Мир, М., 1979)

[69] А.А. Дедкова, М.О. Никифоров, С.В. Митько, В.Ю. Киреев. Российские нанотехнологии, 14 (3-4), 93 (2019). DOI: 10.21517/1992-7223-2019-3-4-93-100 [A.A. Dedkova, M.O. Nikiforov, S.V. Mitko, V.Yu. Kireev. Nanotechnologies in Russia, 14 (3-4), 176 (2019). DOI: $10.1134 / \mathrm{S} 1995078019020046]$

[70] J.D. Baek, Y. Yoon, W. Lee, P. Su. Energy Environ. Sci., 8 (11), 3374 (2015). DOI: 10.1039/C5EE02328A

[71] Н.Е. Ольховский. Предохранительные мембраны (Химия, М., 1976) 